\title{
Transport von infektiösem Material
}

Infektiöses Material wird aus verschiedenen Gründen innerhalb eines Landes oder zwischen den Ländern transportiert. Zum Beispiel werden im Rahmen von internationalen Forschungsprojekten (Blut- und Gewebeproben, Virus-, Bakterien- und Pilzstämme, Plasmide oder andere biologische Materialien) ausgetauscht. Im Rahmen der Bestätigungsdiagnostik durch nationale oder internationale Referenzlaboratorien werden diagnostische Proben und Referenzstämme ausgetauscht. Im Zuge der Transporte ist die klare Zuteilung der Verantwortlichkeiten sowie der sichere Transport durch geeignete Verpackung und Transportwege sehr wichtig. Entsprechend diesen Regelungen bestehen in vielen Ländern nationale Gesetze, die jeweils zu berücksichtigen sind. Eine harmonisierte und detaillierte Darstellung zu der Regelung und der fachgerechten Verpackung findet sich in den Empfehlungen der Weltgesundheitsorganisation WHO [20]. 